\title{
Breath test for differential diagnosis between small intestinal bacterial overgrowth and irritable bowel disease: An observation on non-absorbable antibiotics
}

\author{
I Esposito, A de Leone, G Di Gregorio, S Giaquinto, L de Magistris, A Ferrieri, G Riegler
}

\author{
I Esposito, A de Leone, G Di Gregorio, S Giaquinto, L de \\ Magistris, A Ferrieri, G Riegler, Department of Clinical and \\ Experimental Internal Medicine, Second University of Naples, \\ Italy \\ Correspondence to: Dr. Gabriele Riegler, Department of \\ Clinical and Experimental Internal Medicine, Second University \\ of Naples, Italy. gabriele.riegler@unina2.it \\ Telephone: +39-81-5665292 Fax: +39-81-5665112 \\ Received: August 5, 2007 Revised: September 5, 2007
}

\begin{abstract}
AIM: To estimate the prevalence of small intestine bacterial overgrowth (SIBO) among patients with an earlier diagnosis of irritable bowel disease (IBS) in our geographical area, and to collect information on the use of locally acting non-absorbable antibiotics in the management of SIBO.
\end{abstract}

METHODS: A non-interventional study was conducted in 73 consecutive patients with a symptom-based diagnosis.

RESULTS: When the patients underwent a "breath test", $33(45.2 \%)$ showed the presence of a SIBO. After treatment with rifaximin $1200 \mathrm{mg} / \mathrm{d}$ for seven days in 32 patients, $19(59.4 \%)$ showed a negative "breath test" one week later as well as a significant reduction of symptoms, thus confirming the relationship between SIBO and many of the symptoms claimed by patients. In the other 13 patients, "breath test" remained positive, and a further cycle of treatment with ciprofloxacin 500 $\mathrm{mg} / \mathrm{d}$ was given for 7 additional days, resulting in a negative "breath test" in one patient only.

CONCLUSION: (1) about half of the patients with a symptomatic diagnosis of IBS have actually SIBO, which is responsible for most of the symptoms attributed to IBS; (2) only a "breath test" with lactulose (or with glucose in subjects with an intolerance to lactose) can provide a differential diagnosis between IBS and SIBO, with almost identical symptoms; and (3) the use of non-absorbable antibiotics may be useful to reduce the degree of SIBO and related symptoms; it must be accompanied, however, by the correction of the wrong alimentary habits underlying SIBO.

(C) 2007 WJG. All rights reserved.
Key words: Small intestine bacterial overgrowth; Irritable bowel disease; Breath test; Rifaximin; Hydrogen; Nonabsorbable antibiotics

Esposito I, de Leone A, Di Gregorio G, Giaquinto S, de Magistris L, Ferrieri A, Riegler G. Breath test for differential diagnosis between small intestinal bacterial overgrowth and irritable bowel disease: An observation on nonabsorbable antibiotics. World J Gastroenterol 2007; 13(45): 6016-6021

http://www.wjgnet.com/1007-9327/13/6016.asp

\section{INTRODUCTION}

Irritable bowel syndrome (IBS) is a very common diagnosis in gastroenterology that is done on the basis of the Rome II symptomatic criteria. The basic clinical pattern is characterized by abdominal pain and changes in bowel habit, on the basis of which three different variants of IBS are recognized (IBS with stipsis, IBS with diarrhea or IBS with alternated stipsis and diarrhea). No matter which variant is diagnosed, $92 \%$ of the patients with IBS complain of abdominal bloating, flatulence and meteorism, three symptoms that are, however, more probably related to a small intestine bacterial overgrowth (SIBO) rather than to IBS.

A close relationship exists between the changes in pattern and distribution of gastrointestinal (GI) bacterial flora, and the altered GI motility (changes in bowel habit) and sensorial physiology (abdominal pain and bloating) observed in patients with IBS. It has been demonstrated that the myoelectric activity of intestinal loops are deeply modified by the presence of SIBO, leading to the hypothesis that many of the sensorial and motorial symptoms of IBS are really determined by changes in the GI bacterial flora $^{[1]}$. Moreover, it is well known that both an acute GI infection ${ }^{[2,3]}$ and the use of systemic antibiotics ${ }^{[4,5]}$ lead to profound changes in GI bacterial flora, and that both the conditions may result in symptoms (such as abdominal bloating and changes in bowel habit), which look like those of IBS $^{[6-9]}$.

Finally, it has been reported that even one single cycle of systemic antibiotics may provoke long-time sustained alterations of GI physiology $y^{[10]}$, while a treatment with antibiotics specifically addressed to correction of intestinal 
disbiosis is followed by an improvement of IBS- or SIBOrelated symptoms ${ }^{[11]}$. Thus, there is ground to believe that there is a large overlapping between SIBO and IBS, and that many patients with an earlier symptomatic diagnosis of IBS are actually suffering from SIBO. However, the prevalence of SIBO among patients with an initial diagnosis of IBS is not exactly known.

Cuoco and Salvagnini ${ }^{[12]}$ have recently reported in North Italy a $46 \%$ incidence of positive "breath test" (increased hydrogen concentrations in the expired air after oral lactulose administration) among 96 patients with IBS. According to USA-based clinicians, this incidence could be higher than $80 \%{ }^{[13-15]}$, while European investigators have reported an increased GI bacterial flora in $43 \%$ of patients with IBS compared with $12 \%$ of matched-control healthy subjects, without any relationship between degree of disbiosis and severity of altered GI motility and symptoms ${ }^{[16]}$.

The different values in SIBO prevalence observed worldwide among patients with an initial diagnosis of IBS are probably due to the different methods employed to detect the bacterial colonization of the small intestine: a typical and simple clinico-laboratory test ("breath test" with lactulose) in the first two studies ${ }^{[14,15]}$, a more rigorous microbiological, but also methodologically more complicated test (GI bacterial count $\geqslant 10^{5} / \mathrm{mL}$ ) in the third study ${ }^{[16]}$.

Recent studies have provided increasing support for the concept that disturbances in gut flora occur in patients with IBS and that such abnormalities may contribute to IBS-type symptoms ${ }^{[17]}$. In any case, the overlapping of SIBO and IBS and the role eventually played by SIBO in the pathogenesis of the IBS symptoms, are demonstrated by two double-blind placebo-controlled clinical studies, which have shown respectively a $75 \%$ reduction in the GI symptoms and a long-lasting (over $10 \mathrm{wk}$ ) clinical improvement in subjects with IBS, after treatment with nonabsorbable antibiotics with a topical activity limited to the GI tract ${ }^{[18]}$.

Our study is therefore aimed to estimate the prevalence of SIBO in our geographical area (Campania, South Italy) in patients with IBS diagnosed according to the Rome II criteria; the diagnosis of SIBO is established on the basis of a positive "breath test" with lactulose. We have also gathered information on the use of locally active antibiotics in the management of SIBO.

\section{MATERIALS AND METHODS}

This study was purely observational. Within a time interval of 27 mo (January 2005-March 2007), we selected patients of both sexes who came to our medical centre for advice, and had a diagnosis of IBS, because of abdominal pain and discomfort complying with the following characteristics: (1) Three months of continuous or recurring symptoms of abdominal pain or irritation that: (a) may be relieved with a bowel movement; (b) may be coupled with a change in frequency, or (c) may be related to a change in the consistency of stools. (2) Two or more of the following present at least $25 \%$ of time: (a) change in stool frequency $(>3$ bowel movements daily or $<3$ bowel movements weekly); (b) noticeable difference in stool form (hard, loose and watery stools or poorly formed stools); (c) passage of mucous in stools; (d) bloating or feeling of abdominal distention; (e) altered stool passage (e.g. sensations of incomplete evacuation, straining, or urgency).

Patients with severe cardiovascular or respiratory or renal diseases and patients with cancer or under treatment with antibiotics and corticosteroids were excluded. All the patients gave their informed consent to the management of personal data according to the "privacy" regulations.

All the symptoms, either GI or not, were recorded during the first medical visit, and the patients were asked to score the global intensity of symptoms by means of Visual Analogue Scale (VAS) $10-\mathrm{cm}$ long $(0=$ no symptom; $10=$ unbearable symptom). Then, all the patients underwent a "breath test", whose concept is based on a non-invasive measurement of hydrogen $\left(\mathrm{H}_{2}\right)$ concentrations in the expired air.

In the evening before the examination, the patient was required to eat only boiled rise with no sausage or cheese, and grilled meat, to make a careful oral hygiene and to drink only no-gas water. If stipsis was present, the dietary prescriptions were extended to the three days preceding the exam. On the day of the test, the patient was completely fasted, and smoking was forbidden. Immediately before the test two samples of expired air were taken at a 10-min interval to assay the basal hydrogen concentrations in the still fasted subject; then, $75 \mathrm{~g}$ of lactulose were administered and the expired air was sampled every $15 \mathrm{~min}$ in the next 3 consecutive hours. In one subject with intolerance to lactose, the "breath test" has been performed by using $50 \mathrm{~g}$ of glucose and sampling expired air every $10 \mathrm{~min}$ for $2 \mathrm{~h}$.

A positive test required an elevated breath hydrogen concentration higher than $10 \mathrm{ppm}$ over basal values ${ }^{[19]}$; these concentrations are indicative of a bacterial colonization of the small intestine, where bacteria can metabolize nonabsorbable sugars thus producing increased $\mathrm{H}_{2}$ amounts which are eliminated through respiration ${ }^{[20]}$.

The patients with a positive "breath test", were diagnosed as having SIBO and treated with rifaximin polimorph $\mathrm{A}$ (Normix ${ }^{\circledR}$, Alfa Wassermann) at the daily dose of 1200 $\mathrm{mg} /$ die for 7 consecutive days. One week after the end of the treatment, the "breath test" was repeated, and the patients who still showed a positive test, received a further treatment with ciprofloxacin $500 \mathrm{mg} /$ die for additional $7 \mathrm{~d}$. At the end of the second cycle of antibiotic treatment the "breath test" was repeated for the third time.

The demographic characteristics of the patients were described as means and standard deviations (min-max ranges), or frequencies when appropriate. The frequencies of symptoms observed in patients with diagnosis of SIBO and IBS were compared using the $\chi^{2}$ test, and the frequency of positive "breath test" was analyzed by means of the Fisher exact test.

\section{RESULTS}

A summary flow-chart of the employed methodology and the results achieved in our study is shown in Figure 1.

A total of 73 patients with IBS were selected $(28$ males and 45 females). They were aged between 17 and 87 (mean \pm SD, $41.2 \pm 15.8$ years), and their weight and height were $66.8 \pm 12.6 \mathrm{~kg}$ and $167.1 \pm 9.3 \mathrm{~cm}$, 


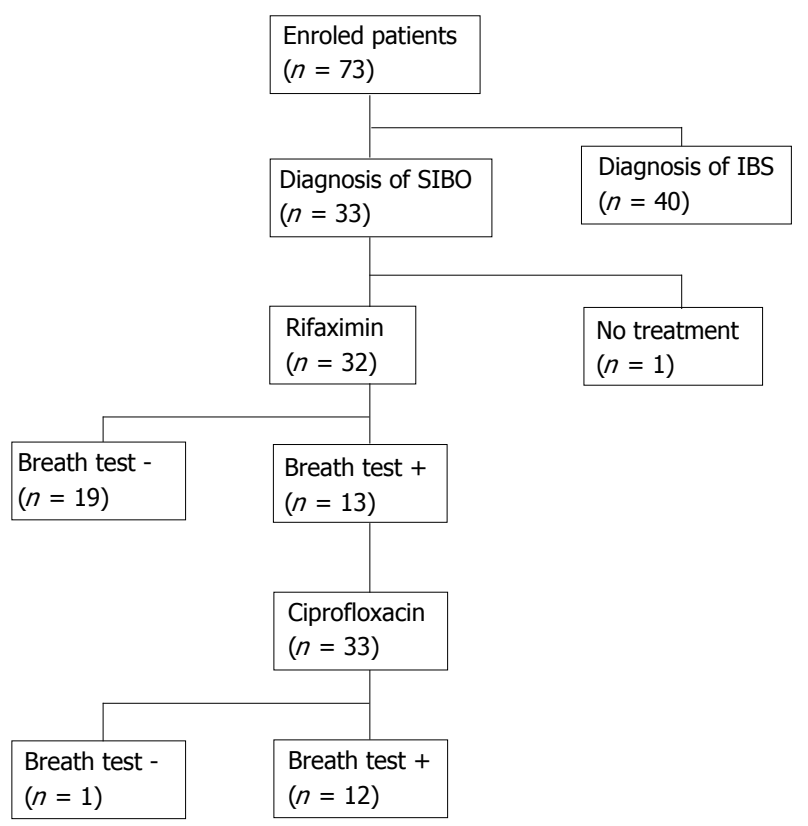

Figure 1 Diagram and synthesis of activities and results in this study.

Table 1 Results of "breath test" with lactulose or glucose in 73 patients with an initial symptoms-based diagnosis of IBS

\begin{tabular}{cccc}
\hline Definitive diagnosis, $\boldsymbol{n}(\%)$ & Breath test & Lactulose & Glucose \\
\hline SIBO $33(45.2 \%)$ & Positive & 32 & 1 \\
IBS $40(54.8 \%)$ & Negative & 40 & 0 \\
\hline
\end{tabular}

The data are reported as frequency and percentage. SIBO: Small intestine bac-terial overgrowth; IBS: Inflammatory bowel disease.

respectively. More than $60 \%$ of males and $50 \%$ of females were younger than 40 , and $10 \%$ of both males and females were older than 60 years.

The symptoms more frequently observed were abdominal bloating $(83.6 \%)$, lower abdominal pain $(76.7 \%)$, flatulence $(65.8 \%)$, tenesmus $(63.0 \%)$ and pain to palpation $(50.7 \%)$, followed with lower frequencies by chronic diarrhoea, upper abdomen pain, nausea, steatorrhea, reduced body weight and stipsis. It is interesting to note that the most frequently observed symptom ("abdominal bloating") is also the most characteristic symptom of SIBO.

When the patients underwent the "breath test" with lactulose (except one patient with intolerance to lactose who received a "breath test" with glucose), 33 (45.2\%) had a positive test, revealing the presence of a clinically relevant bacterial contamination of the small intestine (Table 1).

The symptoms in the patients with a confirmed diagnosis of IBS and those with a diagnosis of SIBO (positive "breath test") are shown in Table 2. The symptomatology was almost superimposable in the two groups, although some symptoms, such as reduced body weight, nausea, pain to palpation, and chronic diarrhoea, were slightly less frequent in subjects with SIBO, while other symptoms, such as tenesmus, were slightly more frequent in the patients with IBS. On the whole, the analysis of the clinical symptoms confirmed that a "breath test" is needed for a differential diagnosis between SIBO and IBS.
Table 2 Frequency of symptoms in $\mathbf{4 0}$ and $\mathbf{3 3}$ patients with a definitive diagnosis of IBS and SIBO respectively

\begin{tabular}{lccc}
\hline & $\begin{array}{c}\text { IBS }(\boldsymbol{n}=\mathbf{4 0}) \\
\boldsymbol{n}(\%)\end{array}$ & $\begin{array}{c}\text { SIBO }(\boldsymbol{n}=\mathbf{3 3 )} \\
\boldsymbol{n}(\%)\end{array}$ & $\boldsymbol{P}$ \\
\hline Chronic diarrhoea & $16(40.0)$ & $17(51.5)$ & NS \\
Upper abdominal pain & $17(42.5)$ & $14(42.4)$ & NS \\
Lower abdominal pain & $30(75.0)$ & $26(78.8)$ & NS \\
Tenesmus & $28(70.0)$ & $18(54.5)$ & NS \\
Pain to palpation & $18(45.0)$ & $19(57.6)$ & NS \\
Abdominal bloating & $32(80.0)$ & $29(87.9)$ & NS \\
Flatulence & $24(60.0)$ & $24(72.7)$ & NS \\
Reduced body weight & $7(17.5)$ & $9(27.3)$ & NS \\
Nausea & $9(22.5)$ & $15(45.4)$ & NS \\
Steatorrhea & $3(7.5)$ & 1 & NS \\
Megaloblastic anemia & 1 & - & NS \\
Stipsis & $8(20.0)$ & $9(27.3)$ & NS \\
Fever & 1 & $2(6.1)$ & NS \\
Other (not specified) & 1 & 0 & NS \\
\hline
\end{tabular}

The data are reported as frequency and percentage.

Table 3 Results of "breath test" and symptom score in 32 patients with defini-tive diagnosis of SIBO treated with rifaximin $1200 \mathrm{mg} / \mathrm{d}$ for $7 \mathrm{~d}$

\begin{tabular}{|c|c|c|c|}
\hline & Before treatment & \multicolumn{2}{|c|}{ After treatment with rifaximin } \\
\hline \multirow[t]{2}{*}{ Breath test } & Positive & Positive & Negative \\
\hline & $32(100.0 \%)$ & $13(40.6 \%)$ & $19(59.4 \%)$ \\
\hline \multirow{5}{*}{$\begin{array}{l}\text { Global } \\
\text { symptom score }\end{array}$} & $3.48 \pm 0.82$ & $3.24 \pm 0.80$ & $0.91 \pm 0.06$ \\
\hline & & NS & $P=0.004$ \\
\hline & & \multirow{3}{*}{$\begin{array}{l}\text { After a further } \\
\text { antibiotic treatment } \\
\text { with ciprofloxacin }\end{array}$} & \\
\hline & & & \\
\hline & & & \\
\hline \multirow{2}{*}{\multicolumn{2}{|c|}{ Breath test }} & Positive Negative & \\
\hline & & 12 & \\
\hline \multicolumn{2}{|c|}{ Global symptom score } & $3.32 \pm 0.95 \quad 1.00$ & \\
\hline
\end{tabular}

The test was repeated one week later and, in the subjects with a still positive "breath test", a further treatment with ciprofloxacin was done (the data are re-ported as frequencies or mean \pm standard deviation as appropriate).

Except one patient who refused further treatment, all the patients showing a positive "breath test" were treated with rifaximin $1200 \mathrm{mg} / \mathrm{d}$ for seven days. Among them, 19 $(59.4 \%)$ patients showed the disappearance of the hydrogen peaks in expired air at the "breath test" one week after the treatment. In these patients, the symptom score was significantly reduced from $3.48 \pm 0.82$ (basal) to $0.91 \pm$ 0.06 after treatment with rifaximin $(P=0.004)$, thus confirming the relationship between SIBO and many of the symptoms claimed by patients (Table 3).

On the contrary, the remaining 13 subjects still showed a positive "breath test" in spite of a treatment with rifaximin, and reported a symptom score $(3.24 \pm 0.80)$ that was almost unchanged compared with the basal values. In these patients, a further antibiotic treatment was given with ciprofloxacin $500 \mathrm{mg} / \mathrm{d}$ for 7 additional days. At the end of the treatment, only one patient showed a negative "breath test", while in the remaining 12 patients the "breath test" was still positive and the symptom score remained unchanged (Table 3).

No adverse effect or adverse drug reaction was observed in our study during the test and/or the medicinal treatment. 


\section{DISCUSSION}

The GI tract is colonized by bacteria immediately after birth $^{[21]}$; Escherichia coli, Streptococci and Clostridi are the first bacteria harboured by the colon, followed by anaerobic Enterococci, Lattobacilli and Bacteroidi $i^{[22]}$. All these bacteria are able to bind the GI mucosa by means of receptors, such as adhesin and lectin, which are expressed either on the host mucosa or other bacteria ${ }^{[23,24]}$, and to resist to the antibacterial activity of many substances that are present in the GI environment, as well as to the gastric acid and GI motility ${ }^{[25]}$.

Many factors affect the type and distribution of the bacteria along the GI tract, starting from the type of delivery $^{[26]}$ and nursing ${ }^{[27]}$ in the first days of life, up to the food habits during adulthood. Normally, bacteria are scarcely present in the acid environment of the stomach while they reach the highest concentrations in the large intestine ${ }^{[28]}$. Moreover, the pattern of bacterial colonization is different among the different segments of the GI tract, the most prevalent being bacteria represented by aerobes and grampositive in the duodenum and proximal ileum ${ }^{[28]}$, gramnegative in the distal ileum, and anaerobes (Bacteroides, Bifidobacteri, Eubacteri and Clostridit) in the colon ${ }^{[28-30]}$.

The role played by the bacterial flora in the normal physiology of the GI tract is known from animal studies performed many years ago ${ }^{[31-34]}$. It is quite clear nowadays that the bacterial flora affects the GI motility by means of three different mechanisms: (a) the release of substances produced or metabolized by bacteria; (b) the involvement of neuroendocrine factors; and (c) the involvement of the GI immunological tissue.

The growth of bacteria is controlled by several mechanisms, including gastric acid secretion, immunological factors, diet and bacterial competition ${ }^{[28,29,35]}$; however, the GI motility is probably the most important factor for control of bacterial growth. It is known that a large part of the bacteria may be eliminated by drugs increasing the GI motility. More importantly, a reduced GI motility leads to bacterial colonization of the small intestine, and many systemic and/or GI diseases characterized by a reduced GI motility have SIBO as one of their consequences ${ }^{[36,37]}$.

In our study, slightly lower than $50 \%$ of patients with an initial diagnosis of IBS, are actually affected by a SIBO that is responsible for many of the symptoms earlier attributed to IBS. Our estimate is almost identical to the $46 \%$ observed by other clinicians in North Italy with similar methods of investigation ${ }^{[12]}$.

Although other investigators have found a lower prevalence using the direct complex method of the GI bacterial count, it should be noted that the "breath test" with lactulose or glucose, with the determination of the hydrogen concentrations in the expired air, is considered an indirect but highly specific, method for diagnosis of $\mathrm{SIBO}^{[38,39]}$. On the other hand, the symptomatology in both SIBO and IBS is almost identical (Table 2) and, therefore, only a "breath test" can help in the differential diagnosis between the two disorders.

Clinicians should be encouraged to perform a "breath test" to promptly identify a SIBO, because the disorder has several systemic consequences ranging from malabsorption of lipids and liposoluble vitamins and loss of electrolytes $^{[22,28]}$, to a more severe translocation of bacteria (usually, gram-negative and aerobic bacteria, such as Escherichia, Proteus, Enterobacter and Klebsiella) from the GI tract to extraintestinal tissues ${ }^{[40]}$, especially in the presence of a pathologically reduced epithelial barrier and immunological defences ${ }^{[41,42]}$. All these factors may lead to sepsis and multiorgan failure ${ }^{[42-46]}$.

The treatment of SIBO must firstly focus on the correction of wrong food and dietary habits that usually underlie the disorder (e.g. excessive use of fast-food), and then to the reduction of bacterial colonization of the small intestine by means of antibiotics ${ }^{[47,48]}$. In this regard, the use of locally acting non-absorbable antibiotics would be particularly useful in reducing immediately the bacterial count waiting for the slow-acting beneficial effects of dietary measures.

In our study, the treatment with rifaximin for one week has determined the negativization of "breath test" in $59.4 \%$ of treated patients. Our data confirm other reports in the most recent literature: at the dose of $800 \mathrm{mg}$ for four weeks rifaximin significantly reduced the symptoms in 20 patients with IBS and led to a negative "breath test" in almost half of patients ${ }^{[49]}$; in another series of 23 patients with SIBO and positive "breath test", a treatment with rifaximin $1200 \mathrm{mg} / \mathrm{d}$ for $7 \mathrm{~d}$ followed by a treatment with probiotics, led to a negative "breath test" in $19(82.6 \%)$ cases and significantly reduced the peak in hydrogen concentrations in the expired air from $40.9 \pm 20.4$ to $4.78 \pm$ $8.42 \mathrm{ppm}^{[12]}$. More evidence on the efficacy of rifaximin has been reported in patients with SIBO and acute diverticulitis of the colon ${ }^{[50]}$, and patients with SIBO and celiac disease ${ }^{[51]}$.

It should be noted that further treatment with ciprofloxacin - an antibiotic widely used in the treatment of IBS $^{[52,53]}$ has not given significantly better results than rifaximin in our experience. Valuable alternatives to rifaximin that have been proven to be effective in the treatment of SIBO are represented by norfloxacin and amoxicillin-clavulanic acid ${ }^{[54]}$, gentamycin ${ }^{[55]}$, trimethoprim/sulfamerazin and polymyxin ${ }^{[56]}$, and chlortetracycline ${ }^{[57]}$.

In conclusion, (1) about half of the subjects with a symptomatic diagnosis of IBS have SIBO as a main cause of their claimed symptoms, which have been initially imputed to IBS; (2) only a "breath test" either with lactulose or with glucose in subjects with intolerance to lactose, can provide a differential diagnosis between IBS and SIBO with identical symptoms; (3) the use of non-absorbable antibiotics is useful in reducing the degree of GI bacterial contamination and related symptomatology, although the correction of wrong dietary habit remains the milestone in the management of SIBO if we want to maintain the results achieved with antibiotic treatment for quite some time.

\section{ACKNOWLEDGMENTS}

We would like to thank Mr. Diego Pappalardo for his valuable technical assistance.

COMMENTS

Background

The role played by the bacterial flora in the normal physiology of gastrointestinal 
(GI) tract is known, and it is quite clear nowadays that the bacterial flora affects the GI motility by means of three different mechanisms: (a) the release of substances produced or metabolized by bacteria; (b) the involvement of neuroendocrine factors; and (c) the involvement of the GI immunological tissues. Recent studies have provided increasing support for the concept that disturbances in gut flora occur in patients with irritable bowel syndrome (IBS) and such abnormalities may contribute to IBS-type symptoms

\section{Research frontiers}

The article provides evidences that in about $50 \%$ of patients with a symptombased diagnosis of IBS, the symptoms are provoked by a small intestine bacterial overgrowth (SIBO).

\section{Innovations and breakthroughs}

Clinicians should be encouraged to perform a "breath test" to promptly identify a $\mathrm{SIBO}$, because the disorder has several systemic consequences of malabsorption of lipids and liposoluble vitamins, and loss of electrolytes.

\section{Applications}

The treatment of SIBO must firstly focus on the correction of wrong food and dietary habits that usually underlie the disorder (e.g. excessive use of fast-food), and then to the reduction of bacterial colonization of small intestine by means of antibiotics. In this regard, the use of locally acting non-absorbable antibiotics would be particularly useful in reducing immediately the bacterial count waiting for the slow-acting beneficial effects of dietary measures.

\section{Terminology}

A standard microbiological definition of SIBO: an increased bacterial count in the small intestine $\geqslant 10^{5}$ colonic bacteria/mL). A positive "breath test": an elevated breath hydrogen concentration within 90 min, two distinct peaks, and an increase higher than $20 \mathrm{ppm}$ over basal values; these concentrations are indicative of a bacterial colonization of the small intestine, where bacteria can metabolize nonabsorbable sugars, thus increasing the $\mathrm{H}_{2}$ amounts which are eliminated through respiration

\section{Peer review}

This report documents the incidence of small bowel overgrowth in patients with irritable bowel syndrome and how their symptoms respond to appropriate antibiotic therapy and whether or not the overgrowth (documented by serial hydrogen breath tests) is eradicated.

\section{REFERENCES}

1 Justus PG, Fernandez A, Martin JL, King CE, Toskes PP, Mathias JR. Altered myoelectric activity in the experimental blind loop syndrome. J Clin Invest 1983; 72: 1064-1071

2 Penny ME, Harendra de Silva DG, McNeish AS. Bacterial contamination of the small intestine of infants with enteropathogenic Escherichia coli and other enteric infections: a factor in the aetiology of persistent diarrhoea? Br Med J (Clin Res Ed) 1986; 292: 1223-1226

3 Tazume S, Ozawa A, Yamamoto T, Takahashi Y, Takeshi K, Saidi SM, Ichoroh CG, Waiyaki PG. Ecological study on the intestinal bacteria flora of patients with diarrhea. Clin Infect Dis 1993; 16 Suppl 2: S77-S82

4 Hooker KD, DiPiro JT. Effect of antimicrobial therapy on bowel flora. Clin Pharm 1988; 7: 878-888

5 Pithie AD, Ellis CJ. Review article: antibiotics and the gut. Aliment Pharmacol Ther 1989; 3: 321-332

6 Barbara G, Stanghellini V, Berti-Ceroni C, De Giorgio R, Salvioli B, Corradi F, Cremon C, Corinaldesi R. Role of antibiotic therapy on long-term germ excretion in faeces and digestive symptoms after Salmonella infection. Aliment Pharmacol Ther 2000; 14: 1127-1131

7 Maxwell PR, Rink E, Kumar D, Mendall MA. Antibiotics increase functional abdominal symptoms. Am J Gastroenterol 2002; 97: 104-108

8 Mendall MA, Kumar D. Antibiotic use, childhood affluence and irritable bowel syndrome (IBS). Eur J Gastroenterol Hepatol
1998; 10: 59-62

9 Spiller RC. Postinfectious irritable bowel syndrome. Gastroenterology 2003; 124: 1662-1671

10 Mangin I, Bourget N, Bouhnik Y, Bisetti N, Simonet JM, Decaris B. Identification of Bifidobacterium strains by rRNA gene restriction patterns. Appl Environ Microbiol 1994; 60: 1451-1458

11 Celik AF, Tomlin J, Read NW. The effect of oral vancomycin on chronic idiopathic constipation. Aliment Pharmacol Ther 1995; 9: 63-68

12 Cuoco L, Salvagnini M. Small intestine bacterial overgrowth in irritable bowel syndrome: a retrospective study with rifaximin. Minerva Gastroenterol Dietol 2006; 52: 89-95

13 Lin HC. Small intestinal bacterial overgrowth: a framework for understanding irritable bowel syndrome. JAMA 2004; 292: 852-858

14 Pimentel M, Wallace D, Hallegua D, Chow E, Kong Y, Park $\mathrm{S}$, Lin HC. A link between irritable bowel syndrome and fibromyalgia may be related to findings on lactulose breath testing. Ann Rheum Dis 2004; 63: 450-452

15 Van Citters GW, Lin HC. Management of small intestinal bacterial overgrowth. Curr Gastroenterol Rep 2005; 7: 317-320

16 Posserud I, Stotzer PO, Björnsson ES, Abrahamsson H, Simrén M. Small intestinal bacterial overgrowth in patients with irritable bowel syndrome. Gut 2007; 56: 802-808

17 Riordan SM, Kim R. Bacterial overgrowth as a cause of irritable bowel syndrome. Curr Opin Gastroenterol 2006; 22: 669-673

18 Noureddin M, Lin HC. Role of gut bacteria in patients with irritable bowel syndrome. J Clin Gastroenterol 2007; 41 (Suppl 1): S33-S36

19 Walters B, Vanner SJ. Detection of bacterial overgrowth in IBS using the lactulose $\mathrm{H} 2$ breath test: comparison with 14C-Dxylose and healthy controls. Am J Gastroenterol 2005; 100: 1566-1570

20 King CE, Toskes PP. Breath tests in the diagnosis of small intestine bacterial overgrowth. Crit Rev Clin Lab Sci 1984; 21 269-281

21 Long SS, Swenson RM. Development of anaerobic fecal flora in healthy newborn infants. J Pediatr 1977; 91: 298-301

22 Drude RB Jr, Hines C Jr. The pathophysiology of intestinal bacterial overgrowth syndromes. Arch Intern Med 1980; 140: 1349-1352

23 Kennedy MJ. Role of motility, chemotaxis, and adhesion in microbial ecology. Ann N Y Acad Sci 1987; 506: 260-273

24 Weissman SJ, Moseley SL, Dykhuizen DE, Sokurenko EV. Enterobacterial adhesins and the case for studying SNPs in bacteria. Trends Microbiol 2003; 11: 115-117

25 Hornef MW, Wick MJ, Rhen M, Normark S. Bacterial strategies for overcoming host innate and adaptive immune responses. Nat Immunol 2002; 3: 1033-1040

26 Grönlund MM, Lehtonen OP, Eerola E, Kero P. Fecal microflora in healthy infants born by different methods of delivery: permanent changes in intestinal flora after cesarean delivery. J Pediatr Gastroenterol Nutr 1999; 28: 19-25

27 Harmsen HJ, Wildeboer-Veloo AC, Raangs GC, Wagendorp AA, Klijn N, Bindels JG, Welling GW. Analysis of intestinal flora development in breast-fed and formula-fed infants by using molecular identification and detection methods. J Pediatr Gastroenterol Nutr 2000; 30: 61-67

28 Simon GL, Gorbach SL. Intestinal flora in health and disease. Gastroenterology 1984; 86: 174-193

29 Berg RD. The indigenous gastrointestinal microflora. Trends Microbiol 1996; 4: 430-435

30 Guarner F, Malagelada JR. Gut flora in health and disease. Lancet 2003; 361: 512-519

31 Abrams GD. Microbial effects on mucosal structure and function. Am J Clin Nutr 1977; 30: 1880-1886

32 Abrams GD, Bishop JE. Effect of the normal microbial flora on gastrointestinal motility. Proc Soc Exp Biol Med 1967; 126: 301-304

33 Iwai H, Ishihara Y, Yamanaka J, Ito T. Effects of bacterial flora on cecal size and transit rate of intestinal contents in mice. Jpn 


\section{J Exp Med 1973; 43: 297-305}

34 WOSTMANN B, BRUCKNER-KARDOSS E. Development of cecal distention in germ-free baby rats. Am J Physiol 1959; 197: 1345-1346

35 Hooper LV, Gordon JI. Commensal host-bacterial relationships in the gut. Science 2001; 292: 1115-1118

36 Nieuwenhuijs VB, Verheem A, van Duijvenbode-Beumer $H$, Visser MR, Verhoef J, Gooszen HG, Akkermans LM. The role of interdigestive small bowel motility in the regulation of gut microflora, bacterial overgrowth, and bacterial translocation in rats. Ann Surg 1998; 228: 188-193

37 Scott LD, Cahall DL. Influence of the interdigestive myoelectric complex on enteric flora in the rat. Gastroenterology 1982; 82: 737-745

38 Bayeli PF, Mariottini M, Lisi L, Ferrari P, Tedone F. [Guidelines on intestinal dysmicrobism (SIBO Small Intestine Bacterial Overgrowth)]. Minerva Gastroenterol Dietol 1999; 45: 297-308

39 Ghoshal UC, Ghoshal U, Das K, Misra A. Utility of hydrogen breath tests in diagnosis of small intestinal bacterial overgrowth in malabsorption syndrome and its relationship with oro-cecal transit time. Indian J Gastroenterol 2006; 25: 6-10

40 Steffen EK, Berg RD, Deitch EA. Comparison of translocation rates of various indigenous bacteria from the gastrointestinal tract to the mesenteric lymph node. J Infect Dis 1988; 157: 1032-1038

41 Berg RD. Bacterial translocation from the gastrointestinal tract. Adv Exp Med Biol 1999; 473: 11-30

42 Madl C, Druml W. Gastrointestinal disorders of the critically ill. Systemic consequences of ileus. Best Pract Res Clin Gastroenterol 2003; 17: 445-456

43 Deitch EA. The role of intestinal barrier failure and bacterial translocation in the development of systemic infection and multiple organ failure. Arch Surg 1990; 125: 403-404

44 Runkel NS, Moody FG, Smith GS, Rodriguez LF, Chen Y, Larocco MT, Miller TA. Alterations in rat intestinal transit by morphine promote bacterial translocation. Dig Dis Sci 1993; 38: 1530-1536

45 Wells CL, Barton RG, Wavatne CS, Dunn DL, Cerra FB. Intestinal bacterial flora, intestinal pathology, and lipopolysaccharide-induced translocation of intestinal bacteria. Circ Shock 1992; 37: 117-123

46 Wells CL, van de Westerlo EM, Jechorek RP, Feltis BA, Wilkins TD, Erlandsen SL. Bacteroides fragilis enterotoxin modulates epithelial permeability and bacterial internalization by HT-29 enterocytes. Gastroenterology 1996; 110: 1429-1437

47 Corazza GR, Sorge M, Strocchi A, Benati G, Di Sario A, Treggiari EA, Brusco G, Gasbarrini G. Non-absorbable antibiotics and small bowel bacterial overgrowth. Ital J Gastroenterol 1992; 24: 4-9

48 Polter DE, Boyle JD, Miller LG, Finegold SM. Anaerobic bacteria as cause of the blind loop syndrome. A case report with observations on response to antibacterial agents. Gastroenterology 1968; 54: 1148-1154

49 Majewski M, Reddymasu SC, Sostarich S, Foran P, McCallum RW. Efficacy of rifaximin, a nonabsorbed oral antibiotic, in the treatment of small intestinal bacterial overgrowth. Am J Med Sci 2007; 333: 266-270

50 Tursi A, Brandimarte G, Giorgetti GM, Elisei W. Assessment of small intestinal bacterial overgrowth in uncomplicated acute diverticulitis of the colon. World J Gastroenterol 2005; 11: 2773-2776

51 Tursi A, Brandimarte G, Giorgetti G. High prevalence of small intestinal bacterial overgrowth in celiac patients with persistence of gastrointestinal symptoms after gluten withdrawal. Am J Gastroenterol 2003; 98: 839-843

52 Guslandi M. Antibiotics for inflammatory bowel disease: do they work? Eur J Gastroenterol Hepatol 2005; 17: 145-147

53 Sartor RB. Therapeutic manipulation of the enteric microflora in inflammatory bowel diseases: antibiotics, probiotics, and prebiotics. Gastroenterology 2004; 126: 1620-1633

54 Attar A, Flourié B, Rambaud JC, Franchisseur C, Ruszniewski P, Bouhnik Y. Antibiotic efficacy in small intestinal bacterial overgrowth-related chronic diarrhea: a crossover, randomized trial. Gastroenterology 1999; 117: 794-797

55 Bhatnagar S, Bhan MK, Sazawal S, Gupta U, George C, Arora NK, Kashyap DK. Efficacy of massive dose oral gentamicin therapy in nonbloody persistent diarrhea with associated malnutrition. J Pediatr Gastroenterol Nutr 1992; 15: 117-124

56 Knoke M, Bernhardt H, Möllmann R, Bootz T. [Therapeutic study of the effect of selective decontamination on microbial overgrowth syndrome of the small intestine]. Gastroenterol J 1989; 49: 59-62

57 Di Stefano M, Malservisi S, Veneto G, Ferrieri A, Corazza GR. Rifaximin versus chlortetracycline in the short-term treatment of small intestinal bacterial overgrowth. Aliment Pharmacol Ther 2000; 14: 551-556

S- Editor Zhu LH $\quad$ L- Editor Ma JY E- Editor Wang HF 